patients who were intraarticular introduced HA with HS. The course of IA injections was 2 for LMW, HMW, and HA with HS, and 3 for MMW HA. Injections were performed with an interval of 1 week. To evaluate the results of treatment, we studied the intensity of pain according to VAS and the total score of KOOS before treatment and on follow-up examinations 1, 3 and 6 months after the course of IA HA injections.

Results: the maximum reduction in pain with IA HA injections at stage I of knee OA occurred by 3 months after the course of treatment. Moreover, improvement was detected by 1 month in $84.3 \%$ of cases, and remained until the end of the study in $71.1 \%$ of patients. All HA preparations used in stage I of knee OA were effective. At stage II of the knee OA after 3 months after the course of IA HA, different efficiencies of HA preparations were revealed. So, in the groups of LMW, MMW and HA with HS, the improvement persisted up to 3 months, and in the group of HMW HA - up to 1 month. After 3 months, the best results were shown by $\mathrm{HA}$ with $\mathrm{HS}$, by 6 months the results were comparable. IA HA injections at the Il stage of knee OA led to good and excellent results 1 month after the course of treatment in $53.9 \%$ of cases, but by the end of the study, improvement remained in only $30.8 \%$ of patients. In the case of the use of HA in stage III of the knee $\mathrm{OA}$, the effectiveness of the studied drugs was comparable, and the maximum improvement was achieved by 1 month. The positive effect of IA HA injections in patients with stage III of the knee OA one month after the course of treatment was obtained in $40.6 \%$ of cases, by 3 months it decreased to $18.8 \%$, and by 6 months - to $15.7 \%$ of patients.

Conclusion: IA injections of $\mathrm{HA}$ at stage I of the knee OA is a highly effective method of conservative treatment, which allows to relieve pain and improve the condition of the knee joint for a period of 6 months or more. The use of HA preparations at stage II of the knee OA allows reducing pain up to 3 months with IA injections of LMW and MMW HA, as well as HA with HS. HMW HA helps reduce pain intensity for a period of 1 month. The use of HA preparations in stage III of the knee OA leads to a short-term relief of symptoms of OA.

Disclosure of Interests: None declared.

DOI: 10.1136/annrheumdis-2021-eular.485

\section{AB0586 \\ PREVALENCE OF EARLY SYMPTOMATIC KNEE OSTEOARTHRITIS ACCORDING TO THREE CLINICAL CLASSIFICATION CRITERIA}

M. Törnblom ${ }^{1,2}$, A. Bremander ${ }^{2,3,4,5}$, K. Aili ${ }^{2,6,7}$, M. Andersson ${ }^{2,4}$, A. Nilsdotter ${ }^{8,9}$, E. Haglund ${ }^{2,4,10}$ on behalf of The Halland Osteoarthritis study group. ${ }^{1}$ Helsingborg Hospital, Department of Rehabilitation, Helsingborg, Sweden; ${ }^{2}$ Spenshult, Research and Development Centre, Halmstad, Sweden; ${ }^{3}$ Department of Regional Health Research, University of Southern Denmark, Odense, Denmark; ${ }^{4}$ Department of Clinical Sciences, Section of Rheumatology, Lund University, Lund, Sweden; ${ }^{5}$ Danish Hospital for Rheumatic Diseases, University Hospital of Southern Denmark, Sønderborg, Denmark; ${ }^{6} \mathrm{Halmstad}$ University, School of Health and Welfare, Halmstad, Sweden; ${ }^{7}$ Karolinska Institutet, Institute of Environmental Medicine, Stockholm, Sweden; ${ }^{8}$ Department of Orthopaedics, Clinical Sciences, Sahlgrenska Academy, Gothenburg University, Göteborg, Sweden; ${ }^{9}$ Sahlgrenska University Hospital, Department of Orthopaedics, Göteborg, Sweden; ${ }^{10}$ Rydberg Laboratory of Applied Sciences, Halmstad University, Halmstad, Sweden

Background: Knee osteoarthritis (KOA) is a heterogeneous disease. Different classification criteria for symptomatic KOA (SKOA) have been proposed. Determining the prevalence and comparing the different criteria of SKOA in patients with knee pain will serve as a base when studying the predictive ability of these criteria in a longer perspective.

Objectives: To study the prevalence of SKOA in individuals with knee pain according to three different classification criteria: the American College of Rheumatology (ACR), (1), the European League Against Rheumatism (EULAR)(2), and the National Institute for Health and Care Excellence (NICE) (3).

Methods: Baseline data from an ongoing longitudinal study (HALLOA) including 296 individuals with knee pain, recruited by advertisement, were analysed. The individuals were categorized according to the classification criteria of SKOA (ACR, EULAR and NICE) based on age, clinical examination (crepitation), and self-reported data from KOOS (pain, symptoms, ADL, and sport/recreation), and dichotomized as fulfilling the criteria (SKOA) or not (no SKOA). BMI was measured $\left(\mathrm{kg} / \mathrm{m}^{2}\right)$. Radiographic KOA (RKOA) was assessed according to Ahlbäck criteria (1-5), defined as RKOA with grade 1 or more in at least one knee. Prevalence was calculated (frequencies, \%) for each criterion, and Chi-Square test or the Independent-Samples t-test were used for comparisons between individuals fulfilling SKOA or not.

Results: The mean age was 52 (min-max 24-73) years, $70 \%$ were women and $22 \%$ were classified with RKOA. The prevalence of SKOA according to each criterion was $57 \%$ (ACR), 51\% (EULAR) and 73\% (NICE) respectively. In total, $48 \%$ had SKOA according to all three criteria and whereof $32 \%$ had RKOA, compared to $10 \%$ RKOA among individuals with no SKOA. Regardless of the criterion, significantly more individuals classified with SKOA also had RKOA compared to individuals with no SKOA, $p<0.001$. Those classified as SKOA were significantly older and had higher BMI compared with no SKOA (Table 1).

Conclusion: Approximately $50-70 \%$ of the individuals with knee pain were classified as having SKOA, where EULAR criteria had the lowest prevalence. A better understanding of early knee pain classification according to different clinica criteria is essential for the ability to capture and follow the long-term prognosis of early SKOA. Further longitudinal studies are needed.

\section{REFERENCES:}

[1] Altman R et al. Arthritis Rheum. 1986;29(8):1039-49.

[2] Zhang W et al. Ann Rheum Dis. 2010;69(3):483-9

[3] Health NIf, Excellence C. UK: National Institute for Clinical Excellence. 2014

Table 1. Comparisons between the ACR, EULAR and NICE criteria of symptomatic knee osteoarthritis, stratified for symptomatic knee osteoarthritis or not

\begin{tabular}{|c|c|c|c|c|c|c|c|c|c|c|}
\hline & & ACR & & & EULAF & & & NICE & & \\
\hline & Total & OA & No OA & P-value & $O A$ & No OA & P-value & OA & No OA & A P-value \\
\hline $\mathbf{N}(\%)$ & $\begin{array}{l}296 \\
(100)\end{array}$ & $\begin{array}{l}170 \\
(57.4)\end{array}$ & $\begin{array}{l}98 \\
(33.1)\end{array}$ & & $\begin{array}{l}152 \\
(51.4)\end{array}$ & $\begin{array}{l}114 \\
(38.5)\end{array}$ & & $\begin{array}{l}215 \\
(72.6)\end{array}$ & $\begin{array}{l}58 \\
(19.6)\end{array}$ & \\
\hline $\begin{array}{l}\text { Age }(Y) \text {, Mean } \\
(S D)\end{array}$ & $\begin{array}{l}751.6 \\
(8.7)\end{array}$ & $\begin{array}{l}53.3 \\
(7.0)\end{array}$ & $\begin{array}{l}49.0 \\
(10.3)\end{array}$ & $<0.001$ & $\begin{array}{l}54.5 \\
(5.1)\end{array}$ & $\begin{array}{l}48.1 \\
(10.8)\end{array}$ & $<0.001$ & $\begin{array}{l}54.7 \\
(4.9)\end{array}$ & $\begin{array}{l}40.5 \\
(9.8)\end{array}$ & $<0.001$ \\
\hline $\begin{array}{l}\text { Gender, } \\
\quad \text { female (\%) }\end{array}$ & $\begin{array}{l}208 \\
(70.3)\end{array}$ & $\begin{array}{l}121 \\
(71.2)\end{array}$ & $\begin{array}{l}66 \\
(67.3)\end{array}$ & 0.511 & $\begin{array}{l}108 \\
(58.4)\end{array}$ & $\begin{array}{l}77 \\
(67.5)\end{array}$ & 0.538 & $\begin{array}{l}154 \\
(71.6)\end{array}$ & $\begin{array}{l}36 \\
(62.1)\end{array}$ & 0.160 \\
\hline $\begin{array}{l}\text { BMI }\left(\mathrm{kg} / \mathrm{m}^{2}\right) \\
\quad \text { Mean }(\mathrm{SD})\end{array}$ & $\begin{array}{l}26.4 \\
(4.6)\end{array}$ & $\begin{array}{l}26.5 \\
(4.5)\end{array}$ & $\begin{array}{l}25.8 \\
(4.3)\end{array}$ & 0.179 & $\begin{array}{l}26.9 \\
(4.5)\end{array}$ & $\begin{array}{l}25.4 \\
(4.2)\end{array}$ & 0.005 & $\begin{array}{l}26.7 \\
(4.5)\end{array}$ & $\begin{array}{l}24.8 \\
(3.8)\end{array}$ & 0.004 \\
\hline RKOA, $n(\%)$ & $\begin{array}{l}64 \\
(21.6)\end{array}$ & $\begin{array}{l}45 \\
(26.5)\end{array}$ & $\begin{array}{l}12 \\
(12.2)\end{array}$ & 0.003 & $\begin{array}{l}47 \\
(30.9)\end{array}$ & $\begin{array}{l}10 \\
(8.7)\end{array}$ & $<0.001$ & $\begin{array}{l}58 \\
(27.0)\end{array}$ & $1(1.7)$ & $<0.001$ \\
\hline
\end{tabular}

Independent-samples t-test and Chi-2-test. Bold=Significant correlation $(p \leq 0.05)$. OA = Osteoarthritis. $\mathbf{A C R}=$ American College of Rheumatology. EULAR = the European League Against Rheumatism. NICE $=$ the National Institute of Care and Excellence. BMI = Body Mass Index. RKOA = Radiographic Knee Osteoarthritis (Ahlbäck, with grade $\geq 1$ in $\geq 1$ knee).

Disclosure of Interests: None declared.

DOI: 10.1136/annrheumdis-2021-eular.520

\section{AB0587 $\quad$ ASSESSING THE CHARACTERISTICS AND MANAGEMENT OF KNEE OSTEOARTHRITIS PATIENTS WITH HYPERTENSION BY CLINICIAN SPECIALITY}

D. Baldock ${ }^{1}$, E. Baynton2, C. F. Ng ${ }^{3} .{ }^{1}$ Ipsos MORI, Healthcare Service Line, Iondon, United Kingdom; ${ }^{1}$ Ipsos MORI, Healthcare Service Line, Iondon, United Kingdom; ${ }^{3}$ Ipsos Sdn Bhd, Healthcare Service Line, Kuala Lumpur, Malaysia

Background: Though the pathogenesis of knee osteoarthritis (OA) is complex patients with $\mathrm{OA}$ frequently have other comorbidities, including hypertension, which eludes to other considerations needed when deciding appropriate treatment management.

Objectives: This study aims to examine the profiles of knee OA patients with hypertension vs. those without any comorbidities, and to elucidate key differ ences between these patient groups as potential areas of consideration.

Methods: A multi-center, online medical chart review study of patients with OA was conducted between May - July 2020 among US rheumatologists (rheums) orthopedic surgeons (orthos), primary care physicians with a focus in sports medicine (SM PCPs), and pain specialists. Physicians recruited were screened for duration of practice in their specialty (3-50 years) and caseload ( $>=35 \mathrm{knee}$ OA patients personally managed, at least 10 being moderate-severe). Patient charts were recorded for the next 5 eligible patients seen during the screening period. Respondents abstracted patient demographics and treatments used Descriptive statistics were used to analyse the data.

Results: 260 physicians were recruited and collectively reported 796 knee OA patients; 559 were reported to experience hypertension whilst 237 were reported as not experiencing any comorbidities.

Reported hypertension patients were significantly older (mean 67 vs 59 years old, respectively; $\mathrm{p} \leq 0.01$ ) and weighed more (mean $82 \mathrm{~kg}$ vs $77 \mathrm{~kg}$, respectively $\mathrm{p} \leq 0.01$ ) than patients without comorbidities; they were also significantly more likely to be previous smokers compared to those without comorbidities (23\% vs $8 \%$, respectively; $p \leq 0.01$ ). With regards to current knee OA severity, both orthos and SM PCPs reported a significantly higher proportion of hypertension patients that were deemed 'severe' (physician opinion) vs patients without comorbidities (orthos: $50 \%$ vs $32 \%$, respectively; SM PCPs: $42 \%$ vs $23 \%$, respectively; $p \leq 0.01$ ) Rheums and pain specialists reported greater mild opioid usage amongst hypertension patients compared to those without comorbidities (rheums: $28 \%$ vs $10 \%$, respectively ( $p \leq 0.05)$; pain specialists: $40 \%$ vs $9 \%$, respectively; $(p \leq 0.01)$ ); orthos and SM PCPs stated significantly greater use of corticosteroid injections amongst their reported hypertension patients vs those without comorbidities (orthos: $60 \%$ vs $41 \%$, respectively; SM PCPs: $40 \%$ vs $19 \%$, respectively; $p \leq 0.01$ ) Hypertension patients reported by orthos and SM PCPs are more likely to be 
considered for total knee replacement (TKR) surgery compared to those without comorbidities (orthos: $59 \%$ vs $32 \%$, respectively; SM PCPs: $37 \%$ vs $19 \%$, respectively; $\mathrm{p} \leq 0.01)$. Conversely, hypertension patients reported by rheums are less likely to be considered for TKR vs those without comorbidities ( $41 \%$ vs $18 \%$, respectively; $\mathrm{p} \leq 0.05$ )

Reported hypertension patients had a significantly higher mean Visual Analogue Scale for Pain (VAS) score than patients without comorbidities (6.6 vs 5.9 , respectively; $p \leq 0.01)$. A significantly higher proportion of patients with hypertension demonstrate radiographic evidence of bone erosion compared to those without comorbidities ( $69 \%$ vs $56 \%$, respectively; $p \leq 0.01$ ).

Conclusion: From the sample surveyed, knee OA patients with hypertension may require a more specific and holistic treatment approach that takes into account their CV status and managing physician specialty. Further investigation using comparator cohort is warranted.

REFERENCES:

[1] Ipsos Osteoarthritis Therapy Monitor (May - July 2020, 260 specialists reporting on 769 knee OA patients seen in consultation, data collected online. Participating physicians were primary treaters and saw a minimum number of 35 knee OA patients). Data (C Ipsos 2021, all rights reserved.

[2] Ipsos Osteoarthritis Therapy Monitor (May - July 2020, 260 specialists reporting on 769 knee OA patients seen in consultation, data collected online. Participating physicians were primary treaters and saw a minimum number of 35 knee OA patients). Data (C) Ipsos 2021, all rights reserved.

Disclosure of Interests: None declared.

DOI: 10.1136/annrheumdis-2021-eular.549

\section{AB0588 (SIR) REGISTER ON OSTEOARTHRITIS (OA): PRELIMINARY DATA}

G. Gigliucci ${ }^{1}$, O. De Lucia $^{2}$, A. Fioravanti ${ }^{3}$, F. Galluccio ${ }^{4}$, S. Guiducci ${ }^{5}$, A. Moretti ${ }^{6}$, M. Matucci-Cerinic ${ }^{5}$, A. Murgo ${ }^{2}$, S. Parisi ${ }^{7}$, R. Ramonda ${ }^{8}$, S. Tenti ${ }^{3}$, E. Tirri ${ }^{9}$, A. Migliore ${ }^{1}$ on behalf of Study group on osteoarthritis - Italian Society of Rheumatology (SIR). ' San Pietro Hospital, Rheumatology Unit, Roma, Italy; ${ }^{2}$ ASST Gaetano Pini-CTO Institute, Division of Clinical Rheumatology, Milan, Italy; ${ }^{3}$ Azienda Ospedaliera Universitaria Senese - Policlinico Le Scotte, Department of Medicine, Surgery and Neuroscience - Rheumatology Unit, Siena, Italy; ${ }^{4}$ Careggi University Hospital - University of Florence, Department of Clinical and Experimental Medicine - Division of Rheumatology, Firenze, Italy; ${ }^{5}$ Careggi University Hospital - University of Florence, Department of Clinical and Experimental Medicine - Department of Geriatric Medicine - Division of Rheumatology and Scleroderma Unit, Firenze, Italy; ${ }^{6}$ University of Campania Luigi Vanvitelli, Multidisciplinary Department of Medical and Surgical Specialties and Dentistry, Naples, Italy; ${ }^{7}$ Azienda Ospedaliero-Universitaria Città della Salute e della Scienza di Torino, Department of General and Specialty Medicine - Unit of Rheumatology, Turin, Italy; ${ }^{8}$ University of Padova, Department of Medicine-DIMED - Rheumatology Unit, Padova, Italy; ${ }^{9} \mathrm{Hospital}$ San Giovanni Bosco, UOSD Reumatologia, Naples, Italy

Background: In Italy Osteoarthritis (OA) is a widespread and disabling disease that affects an increasingly large number of patients in the population, representing one of the main causes of morbidity and disability with high socio-economic costs. The etiology of $O A$ is multifactorial, even if the significant association with some modifiable risk factors like mechanical overload and obesity is now well demonstrated. Early diagnosis and treatment strategies in OA could reduce both patient morbidity and associated costs.

Objectives: Promoted by the Italian Society of Rheumatology (SIR), The Early Symptomatic OsteoaRThritis (ESORT) registry has the aim to study the natural history of OA from the earliest stages (pre- radiographic) considering risk factors in the progression of the disease, and the influence of therapeutic factors on long-term disease outcomes. The ESORT register aims to describe the socio-demographic and clinical characteristics of patients affected by OA in Italy; evaluates the extent of symptoms, functional damage, comorbidities, the frequency of use of drugs currently indicated in our country, and differences related to clinical subsets according with comorbidities and geographical localization of the patient. Methods: Actually 8 Italian Rheumatology centers are involved in the online data entry data of the SIR registry (developed and validated by SIR Study Center), considering patients affected by $\mathrm{OA}$. In particular, the electronic database collects information about main demographic variables, significant anamnestic elements (risk factors and comorbidities), localization of OA, laboratory data, clinimetric indices with WOMAC / FIHOA / VAS scales, radiographic instrumental data and therapy in act. These data are reported in specific forms in the register with annual reassessment.

Results: Currently, 318 patients with OA are included in the "ESORT" registry with an extension of observation up to 48 months, 214 women and 104 men with an average age of 71 years and an average weight of $72 \mathrm{~kg}$. About $14 \%$ of patients affected by knee OA show Kellgren and Lawrence radiological stage 0 in presence of painful symptoms at the knees. The most frequent localization of
OA is the knee $(63 \%)$, followed by the hip (41\%), hand $(36 \%)$, spine $(34 \%)$, and other sites (16\%). The Table 1 shows details of some parameters (average age, average weight, intake of NSAIDs, intake of opioids and intake of chondroprotectors) according to the localization of the disease. From the registry data, patients with OA results treated mainly with NSAIDs and chondroprotectors, and patients with knee OA are the most frequently treated with opioid analgesics (44\%), less used in other OA locations.

Conclusion: The "ESORT" register is a useful tool for epidemiological and clinical information relating to patients with $\mathrm{OA}$ and for monitoring the evolution of the disease and the response to therapy.

\begin{tabular}{llllll}
\hline & $\begin{array}{l}\text { Average age } \\
\text { (years) }\end{array}$ & $\begin{array}{l}\text { Average } \\
\text { weight (kg) }\end{array}$ & $\begin{array}{l}\text { Intake of } \\
\text { NSAIDs (\% of opioids (\% of } \\
\text { patients) }\end{array}$ & $\begin{array}{l}\text { Intake of } \\
\text { patients) }\end{array}$ & $\begin{array}{l}\text { Intake of chon- } \\
\text { droprotectors } \\
\text { (\% of patients) }\end{array}$ \\
\hline OA hand & 70 & 67 & $74 \%$ & $10 \%$ & $25-31 \%$ \\
OA knee & 74 & 75 & $85 \%$ & $44 \%$ & $53-59 \%$ \\
OA hip & 69 & 70 & $75 \%$ & $25 \%$ & $24-28 \%$ \\
OA spine & 75 & 75 & $76 \%$ & $14 \%$ & $19-28 \%$ \\
$\begin{array}{l}\text { OA other } \\
\text { localization }\end{array}$ & 74 & 73 & $69 \%$ & $13 \%$ & $15-35 \%$ \\
\hline
\end{tabular}

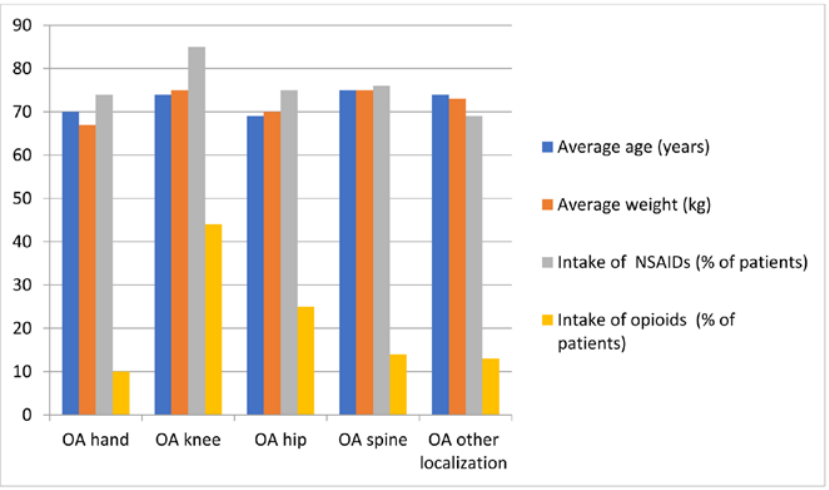

Disclosure of Interests: Gianfranco Gigliucci: None declared., Orazio De Lucia: None declared., Antonella Fioravanti: None declared., Felice Galluccio: None declared., Serena Guiducci: None declared., Antimo Moretti: None declared., Marco Matucci-Cerinic Speakers bureau: Consulting fees or honorarium from Actelion, Janssen, Inventiva, Bayer, Biogen, Boehringer, CSL Behring, Corbus Galapagos, Mitsubishi, Samsung, Regeneron, Acceleron, MSD, Chemomab, Lilly, Pfizer, Roche, Grant/research support from: Consulting fees or honorar ium from Actelion, Janssen, Inventiva, Bayer, Biogen, Boehringer, CSL Behring, Corbus, Galapagos, Mitsubishi, Samsung, Regeneron, Acceleron, MSD, Chemomab, Lilly, Pfizer, Roche, Antonella Murgo: None declared., Simone Parisi Speakers bureau: Personal fees (as speaker and/or consultant) from NOVARTIS, BMS LILLY, UCB, MSD, PFIZER, ABBVIE, BIOGEN, AMGEN, JANSENN CILAG, CHIESI and GRUNENTHAL outside the submitted work; Consultant of: Personal fees (as speaker and/or consultant) from NOVARTIS, BMS, LILLY, UCB, MSD, PFIZER, ABBVIE, BIOGEN, AMGEN, JANSENN CILAG, CHIESI and GRUNENTHAL outside the submitted work;, Roberta Ramonda: None declared., Sara Tenti: None declared., Enrico Tirri: None declared., Alberto Migliore Speakers bureau: Grants from Abiogen,Lilly,Fidia,Jansen (outside the submitted work), Consultant of: Grants from Abiogen,Lilly,Fidia,Jansen (outside the submitted work), Grant/research support from: Grants from Abiogen,Lilly,Fidia,Jansen (outside the submitted work).

DOI: 10.1136/annrheumdis-2021-eular.100

\section{AB0589 $\quad$ STUDY OF THE EFFECTIVENESS OF PELOID THERAPY IN THE TREATMENT OF OSTEOARTHRITIS OF THE KNEE JOINTS IN THE CONDITIONS OF THE SANATORIUM " CHUVASHIYAKURORT》}

N. Zhuravleva ${ }^{1}$, L. Karzakova ${ }^{1}$, S. Kudryashov ${ }^{1}$, A. Arkhipova ${ }^{2} .{ }^{1}$ Federal State Budgetary Educational Institution of Higher Education "The Chuvash State University named after I.N. Ulyanov", Department of Internal Medicine, Cheboksary, Russian Federation; ${ }^{2}$ Budget Institution "Republican Clinical Hospital" of Public Health Ministry of the Chuvash Republic, rheumatology department, Cheboksary, Russian Federation

Background: Peloids are successfully used in the treatment of various diseases. The sapropel mud-silt deposits of freshwater reservoirs are the most widely used for joint diseases. The sapropel mud from the freshwater lake «Kogoyar» 